\title{
PENGETAHUAN DAN SIKAP SEBAGAI PREDISPOSISI PERILAKU MEROKOK PADA KOMUNITAS VAPER
}

\author{
I Gede Purnawinadi $^{1}$, Joshua Edward Gerson Kumayas ${ }^{2}$ \\ ${ }^{1,2}$ Fakultas Keperawatan, Universitas Klabat, Airmadidi, Minahasa Utara, 95371, Indonesia \\ E-mail: purnawinadi87@unklab.ac.id
}

\begin{abstract}
The Electric cigarette is a device created to convert nicotine into smoke that is different from ordinary cigarettes. World Health Organization (WHO) termed e-cigarettes as Electronic Nicotine Delivery System (ENDS). Smoking behavior can be influenced by various factors including knowledge and attitudes. The purpose of this study was to determine the relationship between knowledge and attitudes with the behavior of electric cigarette users in Airmadidi District. The research design used was an analytic survey with a cross-sectional approach. The sampling technique used was accidental sampling with a sample of 63 respondents who used electric cigarettes. The process of collecting data using a questionnaire, and tested statistically using the Spearman correlation formula with a significant $95 \%$ ( $\alpha$ $<0.05 \%)$. The results of the study for the relationship of knowledge and behavior of e-cigarette users showed a value of $p=0.164>0.05$, which means there was no relationship between the knowledge and behavior of e-cigarette users in the District of Airmadidi, while for the relationship of attitudes with the behavior of e-cigarette users showed a value of $p=0,00<0.05$ with a correlation coefficient $(r)$ of 0.724 , which means that there is a significant relationship between the attitudes and behavior of electric cigarette users in Airmadidi District. Recommendations for e-smokers are expected to change attitudes and behavior gradually to avoid the dangers of e-cigarettes.
\end{abstract}

Keywords: Knowledge, Attitude, Behavior, Vaper.

\begin{abstract}
Abstrak
Rokok elektrik merupakan suatu alat yang diciptakan untuk mengubah nikotin menjadi asap berbeda dari rokok biasa. World Health Organization (WHO) mengistilahkan rokok elektrik sebagai Electronic Nicotine Delivery System (ENDS). Perilaku merokok dapat dipengaruhi oleh berbagai faktor diantaranya adalah pengetahuan dan sikap. Tujuan penelitian ini adalah untuk mengetahui hubungan antara pengetahuan dan sikap dengan perilaku pengguna rokok elektrik di Kecamatan Airmadidi. Desain penelitian yang digunakan adalah survei analitik dengan pendekatan cross-sectional. Teknik sampling yang digunakan adalah Accidental sampling dengan jumlah sampel 63 responden yang menggunakan rokok elektrik. Proses pengumpulan data menggunakan kuesioner, dan diuji statistik menggunakan rumus Spearman correlation dengan signifikan $95 \%(\alpha<0,05 \%)$. Hasil penelitian untuk hubungan pengetahuan dan perilaku pengguna rokok elektrik menunjukkan nilai $\mathrm{p}=0,164>0,05$ yang artinya tidak ada hubungan antara pengetahuan dan perilaku pengguna rokok elektrik di Kecamatan Airmadidi, sedangkan untuk hubungan sikap dengan perilaku pengguna rokok elektrik menunjukkan nilai $\mathrm{p}=0,00<0,05$ dengan nilai koefisien korelasi (r) 0,724 yang artinya ada hubungan yang signifikan antara sikap dan perilaku pengguna rokok elektrik di Kecamatan Airmadidi. Rekomendasi untuk perokok elektrik diharapkan untuk mengubah sikap dan perilaku secara bertahap agar terhindar dari bahaya rokok elektrik.
\end{abstract}

Kata Kunci: Pengetahuan, Sikap, Perilaku, Vaper. 


\section{Pendahuluan}

Rokok menjadi salah satu penyebab masalah kesehatan secara global. Data yang ditunjukkan oleh World Health Organisation (WHO), bahwa perokok di dunia sebanyak 2,5 milyar, dua pertiga perokok tersebut berada di negara berkembang. Sedikitnya satu dari empat penduduk dewasa di negara dengan pendapatan perkapita rendah merupakan perokok, paling banyak pada kelompok dewasa muda dengan perbandingan laki-laki lebih tinggi daripada perempuan (Tanuwihardja \& Susanto, 2012). Merokok menyebabkan terjadinya dan berkembangnya berbagai penyakit, seperti faktor risiko independen aterosklerosis kardiovaskular. Beberapa tahun terakhir, rokok elektronik telah menjadi alternatif yang populer karena teknik mikroelektronik modern, selain nyaman dan modis. Meskipun demikian, komentar tentang keamanan rokok elektronik tetap kontroversial (Zhang, Wang, Hou, Xing, Yu, \& Liu, 2018).

Rokok elektrik diciptakan oleh salah satu perusahaan Cina tahun 2003, melalui perkembangan cepat ke seluruh dunia dengan berbagai jenis nama dagang seperti NJOY, Epuffer, blu cig, green smoke, smoking everywhere, dan lain-lain (Damayanti, 2016). Kemenetrian kesehatan Jepang menemukan karsinogen dalam uap yang dihasilkan setelah menghisap rokok elektrik, Asetaldehida ( $\mathrm{CH} 3 \mathrm{CHO})$ didapati pada tingkat yang lebih tinggi dibandingkan rokok tembakau (El Hasna , Cahyo, \& Widagdo, 2017).

Hasil penelitian dari Alawiyah (2017) tentang pengguna rokok elektrik pada komunitas vaper di kota Tanggerang menunjukan $86,3 \%$ laki-laki dewasa beralih dari rokok tembakau ke rokok elektrik. $45,2 \%$ responden memiliki ketergantungan nikotin sangat rendah, $50,7 \%$ responden mempunyai persepsi yang positif tentang rokok elektrik sebesar, 53,4\% responden mengetahui definisi rokok elektrik dengan tepat, $50,7 \%$ responden menganggap rokok elektrik tidak mengandung bahan yang begitu berbahaya, $60,3 \%$ responden beranggapan rokok elektrik menjadi alternatif untuk berhenti dari rokok tembakau, 54,8\% responden mengetahui rokok elektrik berdampak buruk bagi kesehatan. $52,1 \%$ responden menggunakan rokok elektrik karena pengaruh lingkungan atau teman yang menggunakan rokok elektrik, serta mengikuti perkembangan jaman yang ada.

Penelitian yang dilakukan oleh Anto, Umboh, Joseph, dan Ratag (2014) menemukan bahwa mayoritas remaja memiliki pengetahuan yang baik tentang bahaya rokok $(91,4 \%)$, namun tidak sesuai dengnan sikap dan tindakan remaja, sebagian besar dalam kategori kurang baik (65,7\%). Hasil dari penelitian ini menunjukkan tidak terdapat hubungan yang signifikan antara pengetahuan tentang bahaya merokok dengan perilaku merokok, namun terdapat hubungan yang signifikan antara sikap dengan perilaku merokok remaja di Pasar Bersahati kota Manado, hal ini terjadi karena sikap remaja untuk merokok dan untuk mencoba merokok sangat besar, dengan hasil ini dapat kita lihat bahwa pengetahuan belum tentu bisa merubah sikap dan tindakan.

Hasil survei awal yang telah dilakukan peneliti pada komunitas vaper di Kecamatan Airmadidi, didapati sekitar 42 orang yang menggunakan rokok elektrik, dan saat dilakukan wawancara mengenai penggunaan rokok elektrik tersebut, sebagian besar beranggapan bahwa rokok elektrik mengandung 
nikotin dan racun yang lebih rendah dibandingkan rokok tembakau, sehingga rokok elektrik lebih aman. Sehubungan dengan latar belakang tersebut, maka peneliti temotivasi untuk melakukan penelitian mengenai hubungan antara pengetahuan dan sikap sebagai predisposisi perilaku merokok pada komunitas vaper.

\section{Metode}

Penelitian ini merupakan survei analitik dengan pendekatan Cross Sectional, yakni jenis penelitian yang bertujuan untuk menjelaskan suatu hubungan, dimana subjek penelitian hanya dilakukan pengukuran saat penelitian berlangsung (Notoatmodjo, 2008). Sampel dalam penelitian adalah semua pengguna rokok elektrik di Kecamatan Airmadidi yang tergabung dalam komunitas vaper yang berjumlah 63 orang. Teknik sampel pada penelitian ini ditentukan dengan yaitu total sampling yaitu jumlah sampel sama dengan populasi. Jumlah populasi yang kurang dari 100, seluruhnya dapat dijadikan sampel penelitian (Notoadmodjo, 2010).

Penelitian ini menggunakan peralatan atau instrumen yang menunjang jalannya penelitian dengan baik. Adapun instrumen yang digunakan yaitu kuesioner yang diadaptasi dari penelitian Hasriani (2015). Pengetahuan memiliki 10 pernyataan, sikap 10 pernyataan, dan perilaku memiliki 10 pertanyaan. Peneliti kemudian melakukan pilot study nilai $\mathrm{r}$ hitung dari 10 pernyataan kuesioner sikap > nilai $\mathrm{r}$ tabel $(0,308$ $\mathrm{n}=41$ ), sehingga semua pernyataan pada kuesioner sikap dinyatakan valid dan nilai Croncbach's alpha 0,896>0,6 sehingga dinyatakan reliabel.

Data yang diperoleh dijaga kerahasiaan pribadi responden dengan menggunakan inisial. Prinsip etik dalam penelitian ini diterapkan melalui pemberikan informed consent, diawalai dengan penjelasan tmengenai hak serta kewajiban sebagai responden. Data diolah secara deskriptif melalui analisis univariat melalui distribusi frekuensi, kemudian analisis bivariat menggunakan rumus statistik Spearman Correlation pada komputer yang sudah dilengkapi software Statistical Product and Service Solution (SPSS).

\section{Hasil}

Gambaran pengetahuan, sikap, dan perilaku meokok pada komunitas vaper di Kecamatan Airmadidi dapat dilihat pada tabel-tabel berikut:

\section{Tabel 1. Distribusi Frekuensi Gambaran Pengetahuan Pengguna Rokok Elektrik}

\begin{tabular}{lcc}
\hline Kategori & Frekuensi & $\%$ \\
\hline Kurang & 18 & 28,6 \\
Cukup & 16 & 25,4 \\
Baik & 29 & 46,0 \\
Total & 63 & 100 \\
\hline
\end{tabular}

Gambaran pengetahuan dari 63 responden, terdapat 29 responden $(46,0 \%)$ termasuk dalam kategori baik, 16 responden $(24,4 \%)$ termasuk kategori cukup, dan 18 responden $(28,6 \%)$ termasuk dalam kategori pengetahuan kurang.

Tabel 2. Distribusi Frekuensi Gambaran Sikap Pengguna Rokok Elektrik

\begin{tabular}{lcc} 
Kategori & Frekuensi & $\%$ \\
\hline Sangat Baik & 1 & 1,6 \\
Baik & 1 & 1,6 \\
Kurang Baik & 45 & 71,4 \\
Buruk & 15 & 23,8 \\
Sangat Buruk & 1 & 1,6 \\
Total & 63 & 100 \\
\hline
\end{tabular}

Gambaran sikap pengguna rokok elektrik dari 63 responden, terdapat 1 responden $(1,6 \%)$ kategori sangat buruk, 
15 responden $(23,8 \%)$ kategori buruk, 45 responden $(71,4 \%)$ kategori kurang baik, 1 responden $(1,6 \%)$ kategori baik, dan 1 responden $(1,6 \%)$ termasuk dalam kategori sangat baik.

Tabel 3. Distribusi Frekuensi Gambaran Perilaku Pengguna Rokok Elektrik

\begin{tabular}{lcc}
\hline Kategori & Frekuensi & $\%$ \\
\hline Merokok Ringan & 44 & 69,8 \\
Merokok Sedang & 17 & 27,0 \\
Merokok Berat & 2 & 3,2 \\
Total & 63 & 100 \\
\hline
\end{tabular}

Berdasarkan tabel 3. dapat diketahui bahwa dari 63 responden, terdapat 2 responden $(3,2 \%)$ kategori merokok berat, 17 responden $(27,0 \%)$ termasuk dalam kategori merokok sedang, dan 44 responden $(69,8 \%)$ termasuk dalam kategori merokok ringan.

Tabel 4. Hubungan Antara Pengetahuan dengan Perilaku Pengguna Rokok Elektrik

\begin{tabular}{lc}
\hline Spearman's rho & $\begin{array}{c}\text { Pengetahuan dan } \\
\text { Perilaku }\end{array}$ \\
\hline Correlation Coefficient & $0,177^{*}$ \\
Sig. (2-tailed) & 0,164 \\
$\mathrm{~N}$ & 63 \\
*. Correlation is significant at the 0.05 level (2-tailed).
\end{tabular}

Hasil yang diperoleh pada tabel 4. yaitu $p=0,164>0,05$ yang berarti tidak terdapat hubungan yang signifikan antara pengetahuan dengan perilaku pengguna rokok elektrik pada komunitas vaper di Kecamatan Airmadidi.

Tabel 4. Hubungan Antara Sikap dengan Perilaku Pengguna Rokok Elektrik

\begin{tabular}{lc}
\hline Spearman's rho & $\begin{array}{c}\text { Sikap dan } \\
\text { Perilaku }\end{array}$ \\
\hline Correlation Coefficient & $0,724^{*}$ \\
Sig. (2-tailed) & 0,000 \\
$\mathrm{~N}$ & 63 \\
\hline *. Correlation is significant at the 0.05 level (2-tailed).
\end{tabular}

Pada tabel 5. dapat dilihat nilai $p=0,00<$ 0,05 yang berarti ada hubungan yang signifikan antara sikap dan perilaku pengguna rokok elektrik di Kecamatan Airmadidi. Nilai correlation coefficient (r) 0,724 yang artinya keeratan hubungan kedua variabel kuat dengan arah positif, semakin baik sikap individu maka semakin baik perilaku.

\section{Pembahasan}

Hasil penelitian ini berkaitan dengan hasil penelitian terdahulu yang dilakukan oleh Maseda, Suba, dan Wongkar (2013) kepada 128 responden diperoleh 110 remaja putra memiliki pengetahuan tentang rokok yang baik. Berdasarkan hasil wawancara, beberapa pengguna rokok elektrik mengatakan mengetahui bahan nikotin yang dapat mengakibatkan kecanduan dan masalah pada sistem pernapasan yang dapat ditimbulkan akibat mengkonsumsi rokok elektrik, dan sebagian besar pengguna rokok elektrik berpendidikan sebagai mahasiswa. Begitupula dengan penelitian yang dilakaukan oleh Anto, Umboh, Joseph, dan ratag (2014) kepada 35 responden diperoleh 23 responden $(65,7 \%)$ memiliki sikap kurang baik.

Berdasarkan hasil wawancara pada beberapa perokok elektik mengatakan bahwa menggunakan rokok elektrik relatif lebih aman dibandingkan dengan rokok tembakau, sehingga lebih memilih menggunakan rokok elektrik, dan para pengguna rokok elektrik menganggap bahwa sikap itu positif tapi itu justru adalah sikap yang negatif. Hal ini berkaitan dengan motivasi penggunaan rokok elektrik adalah meningkatkan citra diri serta meningkatkan kepercayaan diri (Istiqomah, Cahyo, dan Indraswari, 2016).

Penelitian yang dilakukan oleh Amelia, Nasrul, dan Basyar (2016), didapatkan bahwa perokok dengan derajat ringan 
merupakan kelompok terbanyak yaitu 27 orang $(41,5 \%)$. Berdasarkan hasil wawancara dengan beberapa pengguna rokok elektrik mengatakan bahwa menggunakan rokok elektrik hanya disaat berkumpul dengan anggota komunitas atau hanya disaat ingin menenangkan diri saja dan bukan sebuah rutinitas.

Tidak terdapat hubungan yang signifikan antara pengetahuan dengan perilaku merokok dalam hal ini dapat terjadi dikarenakan sikap remaja untuk merokok yang masih salah dan keinginan untuk mencoba merokok sangat besar, dengan hasil ini dapat kita lihat bahwa pengetahuan yang tinggi tentang bahaya rokok belum tentu dapat merubah sikap dan tindakan. Remaja cenderung mengangkat diri sendiri sebagai individu melalui simbol status seperti pemilihan barang sebagai usaha menarik perhatian agar dipandang individu, sehingga remaja cenderung lebih memperhatikan penampilan. Padahal perilaku merokok tidak akan memperbaiki penampilan tetapi memperburuk penampilan disebabkan bau asap rokok, plak hitam pada gigi, serta warna hitam/gelap pada bibir (Rochayati \& Hidayat, 2015). Meskipun pengguna rokok elektrik memiliki pengetahuan yang baik tentang bahaya rokok elektrik tapi alasan dari pengguna rokok elektrik untuk tetap merokok adalah agar terlihat lebih gaul atau lebih keren.

Penelitian ini sejalan dengan penelitian Anto, Umboh, Joseph, dan Ratag (2014) diperoleh nilai $\mathrm{p}=0,007$ yang artinya terdapat hubungan yang signifikan antara sikap tentang bahaya merokok dan perilaku merokok, begitujuga dengan penelitian yang dilakukan oleh Maseda, Suba, dan Wongkar (2013) diperoleh nilai $\mathrm{p}=0,00$ yang artinya ada hubungan yang signifikan antara sikap dan perilaku merokok. Keputusan dalam menampilkan perilaku tertentu merupakan hasil dari proses berpikir secara rasional yang diarahkan pada tujuan tertentu dengan mengikuti urutanurutan berpikir, kemudian direfleksikan dalam tingkah laku, bahkan menjadi prediktor yang cukup kuat dalam cara individu bertingkah laku dalam situasi yang terjadi (Purwanto, 2015). Jadi sikap setiap individu sangatlah berkorelasi dengan perilaku yang ditampilkan, hubungan ini terletak pada individu itu sendiri terhadap respon yang didapati, kecenderungan individu melakukan tindakan sangat dipengaruhi oleh berbagai faktor bawaan dan lingkungan.

Menurut penelitian Mulyani, Leida, Thaha (2013) sikap merokok dipengaruhi oleh faktor-faktor yang seperti coba-coba/ikut teman, mengikuti trend/mode, pelarian stress, lambang kedewasaan sehingga mempengaruhi perilaku. Berdasarkan hasil wawancara yang dilakukan pada beberapa pengguna rokok elektrik mengatakan bahwa rokok elektrik lebih aman digunakan daripada rokok tembakau sehingga lebih memilih menggunakan rokok elektrik dan perilaku perokok elektrik yaitu menggunakan rokok elektrik hanya disaat berkumpul dengan teman satu komunitas saja atau disaat ingin menenangkan diri.

Harapan dari hasil penelitian kiranya dapat menyadarkan para perokok dan tidak hanya mengetahui bahaya rokok elektrik tetapi juga memahami bahkan mampu mengaplikasikan pengetahuan tentang bahaya rokok elektrik dengan secara bertahap untuk berhenti menggunakan rokok elektrik. Direkomendasikan juga kepada pengguna rokokk elektrik untuk memiliki sikap yang benar dengan secara perlahan untuk berhenti 
menggunakan rokok elektrik. Peneliti selanjutnya yang behubungan dengan variabel penelitian ini dapat menambahkan variabel motivasi, karena yang menjadi motivasi bagi pengguna rokok elektrik untuk menggunakan rokok elektrik berbeda beda.

\section{Referensi}

Alwiyah, S.S. (2017). Gambaran Persepsi Tentang Rokok Elektrik Pada Para Pengguna Rokok Elektrik di Komunitas Vaporiser Kota Tangerang. Repository UINJKT. Diakses tanggal 1 Agustus 2019. Online: http://repository.uinjkt.ac.id/dspac e/bitstream/123456789/35973/1/Sit i\%20Sarah\%20AlawiyahFKIK.pdf

Amelia, R., Nasrul, E., \& Basyar, M. (2016). Hubungan derajat merokok berdasarkan indeks brinkman dengan kadar hemoglobin. Jurnal Kesehatan Andalas, 4(2), 622. Online: http://jurnal.fk.unand.ac.id/index .php/jka/article/view/587

Anto, M. V., Umboh, J. M., Joseph, W. B., \& Ratag, B. (2014). Hubungan antara Pengetahuan dan Sikap tentang Bahaya Merokok dengan tindakan Merokok Remaja di pasar bersahati Kota Manado . Jurnal kesehatan masyarakat, 2.

Damayanti, A. (2016). Penggunaan Rokok Elektrik di Komunitas Personal Vaporizer Surabaya. Jurnal Berkala Epidemiologi, Volume 4, 251-252. http://dx.doi.org/10.20473/jbe.V 4I22016.250-261 Online: https://e-
journal.unair.ac.id/JBE/article/vi ew/2150

El Hasna , F. A., Cahyo, K., \& Widagdo, L. (2017). Faktorfaktor yang berhubungan dengan penggunaan rokok elektrik pada perokok pemuladi sma kota Bekasi. Jurnal kesehatan masyarakat, 7, 3. Online: https://ejournal3.undip.ac.id/ind ex.php/jkm/article/view/17287

Hasriani. (2015). Gambaran Tingkat Pengetahuan, Sikap, dan Tindakan Remaja Wanita Tentang Dampak Merokok Di Club Malam Retro Makassar. Repository Karya Tulis Ilmiah UIN Alaudin Makassar. Diakses tanggal 2 Agustus 2019. Online: http://repositori.uinalauddin.ac.id/4148/1/KTI\%20HA SRIANI.pdf

Istiqomah, D. R., Cahyo, K., dan Indraswari, R. (2016). Gaya Hidup Komunitas Rokok Elektrik Semarang Vaper Corner. Jurnal Kesehatan Masyarakat Vol.4, No.2 April 2016. Diakses tanggal 4 Agustus 2019. Online: https://media.neliti.com/media/pub lications/18679-ID-gaya-hidupkomunitas-rokok-elektriksemarang-vaper-corner.pdf

Maseda, D. R., Suba, B., \& Wongkar, D. (2013). Hubungan Pengetahuan dan Sikap tentang Bahaya Merokok dengan Perilaku Merokok pada Remaja Putra di SMA Negeri 1 Tompaso baru. jurnal keperawatan, 1. Online: https://ejournal.unsrat.ac.id/inde x.php/jkp/article/view/2176

Muliyana, D., Leida, I., \& Thaha, M. (2013). Faktor yang 
berhubungan dengan Tindakan

Merokok pada Mahasiswa

Universitas Hasanudin Makassar. Jurnal Unhas, 112. Online: http://journal.unhas.ac.id/index. php/mkmi/article/view/446

Notoadmodjo, S. (2010). Pendidikan dan Perilaku Kesehatan. Jakarta: Rineka Cipta.

Notoatmodjo, S. (2008). Metodologi Penelitian Kesehatan (Edisi revisi), 2, 179. Jakarta: Rineka Cipta.

Rochayati, A. S., Hidayat, E. (2015).

Faktor-Faktor Yang

Mempengaruhi Perilaku

Merokok Remaja di Sekolah Menengah Kejuruan Kabupaten

Kuningan. Jurnal Keperawatan Soedirman, Vol. 10, No. 1. Diakses tanggal 4 Agustus 2019. Online:

https://media.neliti.com/media/p ublications/104515-ID-faktorfaktor-yang-mempengaruhiperilaku.pdf

Tanuwihardja, R. K., \& Susanto, A. D. (2012). Rokok Elektronik (electronic cigarette). Jurnal Respirasi Indonesia, 54. Diakses tanggal 2 Agustus 2019. Online: http://arsip.jurnalrespirologi.org/e lectronic-cigarettel

Zhang, G., Wang, Z., Hou, R., Xing, C., Yu, Q., and Liu, E. (2018). Safety Assessment of Electronic Cigarettes and Their Relationship with Cardiovascular Disease. International Journal of Environmental Research and Public Health. Jan; 15(1): 75. doi: 10.3390/ijerph15010075.

Retreived from: https://www.ncbi.nlm.nih.gov/pmc/ articles/PMC5800174/ 